\title{
Adquisición y transmisión del mapudungún en hablantes urbanos
}

\author{
Fernando Wittig González*
}

\section{Resumen}

Se presenta un análisis sobre el proceso de adquisición del mapudungún en una muestra diversificada de hablantes urbanos. Con base en un cuestionario sociolingüístico se examinan la secuencia de adquisición de lenguas, los agentes de transmisión y las pautas de interacción con los padres en la socialización temprana del hablante. Los resultados muestran perfiles diferenciados que integran rasgos particulares de cada una de estas dimensiones. Se destaca un grupo de hablantes que adquiere competencia activa en mapudungún como L2 en circunstancias que ponen de relieve la tensión permanente que implica para el hablante asumir un comportamiento socio-lingüístico consecuente con su identificación étnica.

Palabras clave: Bilingüismo, adquisición, mapudungún, hablantes urbanos

\section{Acquisition and transmission of mapudungún in urban speakers}

\begin{abstract}
An analysis is presented on the language-acquisition process in a diversified sample of mapudungun urban speakers. Based on a sociolinguistic survey, we examine the sequence of language acquisition, transmission agents and interaction with parents during early socialization. Results show different profiles integrating particular features from each one of these dimensions. The foremost group of speakers are those who acquire active competence in mapudungun as a second language. The circumstances of their individual processes reveal the permanent tension involved when speakers try to adopt socio-linguistic patterns consistent with their ethnic identification.
\end{abstract}

Keywords: Bilingualism, acquisition, mapudungun, urban speakers 


\section{Introducción}

En los últimos años, se ha manifestado un creciente interés público y académico por el estado de conservación de las lenguas indígenas habladas en Chile. En ese contexto, se han publicado los primeros estudios con muestras representativas que describen la condición minorizada de estas lenguas en relación con la lengua dominante. Para el caso del mapudungún, los últimos estudios ponen énfasis en la condición de lengua en peligro. Gundermann et al. (2009: 51), por ejemplo, sostienen que "la dinámica de la lengua mapuche es la de una transformación tendiente a su desaparición y completo reemplazo por el castellano", aunque reconocen que el proceso no es necesariamente irreversible ni tendría que materializarse en las próximas dos o tres generaciones. Los principales indicadores son: concentración de hablantes en los segmentos de mayor edad, proporciones significativas de hablantes que adquieren el mapudungún como L2, y bajas frecuencias de uso de la lengua, sobre todo en el hogar y en interacciones con niños pequeños (Gundermann, 2005; Zúñiga, 2007; Giannelli, 2008a; Gundermann et al., 2008). Pese a lo anterior, los hablantes expresan actitudes de alta valoración hacia la lengua y manifiestan un interés explícito en los programas formales de enseñanza y/o revitalización del mapudungún (Lagos, 2004; Giannelli, 2008b).

Esta condición de lengua minorizada se presenta de manera más acentuada en el medio urbano, donde se concentra alrededor del 60\% de la población mapuche. Según un estudio de la Corporación Nacional de Desarrollo Indígena (Conadi-Utem, 2009), que consideró una muestra de mil hogares de la Región Metropolitana ${ }^{1}$, el porcentaje de hablantes con algún grado de competencia en mapudungún alcanza el 19,7\% de la población metropolitana, es decir, unas 39 mil personas. La adquisición del mapudungún como Ll representa al 40,1\% de los hablantes urbanos, mientras que la adquisición como L2 representa al $59,9 \%$ restante. Del total de hablantes, una amplia mayoría $(82,2 \%)$ declara competencia activa en la lengua. No obstante, la distribución por categorías auto-evaluativas (satisfactoria, 40,2\%; con dificultades, 20,7\%; y elemental o incipiente, $39,1 \%$ ) indica que el porcentaje de hablantes que puede sostener diálogos fluidos no superaría la mitad de los que se declaran bilingües activos. Los datos de este estudio ilustran también

1 De acuerdo con los datos censales de 2002, en la Región Metropolitana viven alrededor de 180 mil mapuches, la mayor concentración de población mapuche urbana en el país. (Véase www.ine.cl) 
las dificultades que representa el contexto urbano para la transmisión y adquisición de la lengua, pues sólo un 15,9\% de los bilingües activos ha desarrollado tal condición en su medio social de residencia urbana. Todo lo anterior parece confirmar la hipótesis de Salas (1987) en cuanto a que la estrecha relación entre lengua y cultura hace inviable la inserción del mapudungún en situaciones comunicativas ancladas en contextos no tradicionales. En otras palabras, el problema de la vitalidad de la lengua adquiere un matiz crítico frente al proceso sostenido de migración urbana en que se ve envuelta su comunidad de hablantes.

\section{La sociología del lenguaje y el contacto de lenguas}

Existe una amplia bibliografía en sociología del lenguaje y otras disciplinas afines sobre las consecuencias del contacto de lenguas. Los puntos de partida se asocian a los conceptos de diglosia y sus relaciones con el bilingüismo social (Fishman, 1982). Fishman (op. cit.) propone distinguir entre una sociología del lenguaje descriptiva y otra dinámica. La primera, se propone identificar las "estructuras sociales generalmente aceptadas del uso lingüístico, del comportamiento y actitud ante el lenguaje" (op. cit.: 35). La orientación dinámica, en tanto, adopta un carácter explicativo, pues intenta identificar las causas y los factores socioculturales que condicionan las pautas de uso lingüístico a nivel social, tanto en su dimensión sincrónica como diacrónica. A un nivel macro-sociológico, Fishman (1991) propone un conjunto de condiciones estructurales físicodemográficas (migraciones o flujos poblacionales), sociales (desventajas sociales, políticas y económicas que afectan a los grupos minorizados) y culturales (quiebre o transformación de las prácticas culturales del grupo minorizado), que permiten explicar los procesos sociolingüísticos que afectan a las comunidades minorizadas.

El análisis sociolingüístico, en tanto, se concentra en el comportamiento de los hablantes de una comunidad bilingüe, es decir, en las pautas de elección, adquisición y transmisión de lenguas. Estas pautas se relacionan con ámbitos de uso, contextos de socialización, agentes y medios de transmisión, entre otros conceptos operacionales (Fasold, 1996; Moreno Fernández, 2005). El análisis sociolingüístico permite identificar procesos de desplazamiento, conservación y revitalización de las lenguas. El desplazamiento se define como la sustitución gradual de la lengua minorizada en beneficio de la lengua dominante, lo que -en último término- puede conducir a la muerte o desaparición de la lengua. 
La conservación (mantenimiento o continuidad), en tanto, se refiere a una relativa estabilidad de las lenguas en ciertos ámbitos de uso, así como también en el número de hablantes, su distribución según grupos de edad y niveles de fluidez. La revitalización, por último, alude al conjunto de prácticas que buscan restituir total o parcialmente las funciones sociales que la lengua subordinada desempeñaba entre su propia comunidad de hablantes con anterioridad al proceso de desplazamiento. (Hornberger y Coronel-Molina, 2004).

Este marco de referencia no ha estado exento de discusiones y revisiones críticas, las que apuntan principalmente al énfasis funcionalista con que se evalúa el comportamiento de los hablantes y las comunidades minorizadas. Diversos autores han reorientado la discusión hacia los contextos sociolingüísticos indoamericanos, marcados por relaciones de fuerza e ideologías que se proyectan desde los períodos de dominación colonial hasta los contextos sociopolíticos actuales. Hamel (1988) concibe la elección de lenguas en relación con las particularidades de procesos históricos no resueltos que confrontan posiciones de hegemonía y resistencia cultural. En una línea similar, Albó (1988) propuso el concepto de 'idiomas oprimidos' para caracterizar a las lenguas indígenas de acuerdo con el tipo de relación que las vincula con la lengua dominante. Albó (op. cit.) acude a la imagen de la atrofia y la proyecta, por ejemplo, a los planos lingüístico y psico-social. El primero apunta, por ejemplo, al empobrecimiento léxico, la pérdida de oposiciones fonológicas o la alteración de rasgos gramaticales de base; el segundo, en tanto, se refiere a las actitudes de vergüenza y auto-represión de los hablantes frente al poder simbólico del idioma nativo como elemento que identifica a los hablantes con los grupos más desprestigiados de la sociedad nacional. Por último, Coronado (1996) propone una tipología de las pautas de interacción de comunidades lingüísticas subordinadas. La autora sostiene que, en paralelo a la transformación permanente que experimentan las sociedades indígenas en su relación con la sociedad nacional, las comunidades acomodan de modo gradual sus pautas de elección lingüística a tales cambios. Lo anterior implica que algunos espacios sociales se desarrollan como bilingües o monolingües en una u otra lengua. La autora parte del supuesto de que "aún en condiciones de conflicto lingüístico, el bilingüismo como tal puede desarrollarse como una alternativa, ya que las lenguas indias, aún en su carácter de lenguas subordinadas, poseen valores relevantes para el grupo, en tanto la funcionalidad de la lengua no sólo se da en términos comunicativos, sino ligada a procesos sociopolíticos de etnicidad" (Coronado, 1996: 53). 


\section{La investigación}

\subsection{Objetivos}

La investigación que aquí se presenta surge del interés por examinar la situación sociolingüística del mapudungún en contexto urbano a la luz de los planteamientos expuestos en el punto anterior. La investigación considera evaluar los procesos de adquisición y transmisión, las competencias auto-atribuidas y las condiciones de uso del mapudungún en hablantes urbanos. En este artículo, se presentan los resultados obtenidos en relación con las pautas de adquisición y transmisión del mapudungún.

El objetivo de este trabajo es presentar y discutir algunos resultados que describen el proceso de adquisición de la lengua mapuche en hablantes urbanos, específicamente en el marco de la socialización familiar y la experiencia migratoria.

\subsection{Procedimientos}

Se elaboró una muestra diversificada de hablantes urbanos de mapudungún. Como criterios de selección, se fijaron la auto-adscripción étnica, la condición de hablante de mapudungún ${ }^{2}$ y la residencia en Santiago, Concepción o Temuco. ${ }^{3}$ La selección de los participantes se llevó a cabo con la ayuda de dirigentes urbanos y dos colaboradores directos, quienes estaban en posición de identificar y proponer los contactos iniciales. La elaboración definitiva de la nómina de participantes se desarrolló mediante la técnica de muestreo en cadena (Patton, 1990; Johnstone, 2000). La interacción con los entrevistados se realizó en un clima de cordialidad, principalmente en su hogar y en compañía de otros miembros del grupo familiar. El trabajo con los participantes se desarrolló entre agosto de 2006 y diciembre de 2007.

La muestra se configuró con 40 hablantes urbanos: 14 de Concepción (35\%), 8 de Santiago (20\%), y 18 de Temuco (45\%). La muestra incluyó a 24 hombres (60\%) y 16 mujeres (40\%). En relación con la variable 'edad', se dividió la muestra en 3 grupos relativamente homogéneos: 12

2 Se especificó que dicha condición implicaba como requisito esencial la capacidad para participar de manera activa en eventos comunicativos con otros hablantes de mapudungún. Además de la auto-declaración, se utilizaron procedimientos de control indirectos que permitieran asegurar tal condición.

3 Entre los participantes de Temuco, se incluyen personas en la modalidad de doble residencia o que residen en comunidades aledañas y desarrollan actividades en dicha ciudad. 
jóvenes (de 20 a 35 años), 14 adultos (36-50) y 14 mayores (sobre 51 años). La edad de los participantes oscila en un rango de 20 a 78 años, con una edad promedio de 44 años.

En la interacción con los participantes, se aplicó un cuestionario sociolingüístico sobre ámbitos de uso y pautas de transmisión del mapudungún. El cuestionario es una versión adaptada de un instrumento de similares características diseñado por el Centro Interdipartimentale di Studi sull'America Indigena (CISAI) de la Universidad de Siena ${ }^{4}$. Según los tópicos, el cuestionario incluyó preguntas cerradas o abiertas, de opción única o múltiple, preguntas con escala de frecuencia, entre otras. Algunos ejes temáticos abordados fueron los ámbitos y frecuencia de uso del mapudungún, los contextos de adquisición y transmisión, la autoevaluación de competencias, las redes de interlocutores, y evaluaciones sobre la presencia del mapudungún en medios de comunicación, organizaciones socio-políticas y ceremonias rituales en el medio urbano.

\subsection{Resultados}

\subsubsection{Antecedentes socioculturales}

La mayor parte de los hablantes seleccionados $(67,5 \%)$ se crió en una comunidad o reducción; respondieron, por tanto, al perfil de primera generación migratoria. Los casos restantes se dividen entre migrantes de segunda generación (10\%) y la modalidad de doble residencia (22,5\%). En promedio, los participantes acumulan una residencia urbana prolongada (24,8 años). Los antecedentes recogidos sitúan a los migrantes en medio de una transición progresiva de su núcleo familiar inmediato hacia la condición urbana: los padres permanecen en la comunidad de origen; hermanos y parejas se distribuyen entre migrantes y no migrantes; los hijos se concentran en la categoría de segunda generación migratoria.

Los antecedentes muestran una relación previsible entre grupos de edad y niveles de educación: los mayores se concentran en los niveles de escolaridad más bajos y viceversa. No obstante y pese a la amplitud del rango de edad de los participantes, la muestra se concentra en niveles de escolaridad medio-técnico y universitario. De la muestra, 28 hablantes declararon alguna actividad laboral regular al momento de la entrevista. Se registraron actividades diversas, que van desde panaderos y servicio doméstico hasta actividades técnicas y profesionales. En ese contexto, 7

4 Disponible en www.unisi.it/cisai/ll conosud. 
hablantes se dedican a actividades de enseñanza y difusión de la lengua y cultura mapuches en el medio urbano, y otros 7 desempeñan labores que demandan algún grado de uso del mapudungún. Ambas situaciones aparentemente representan contextos sociales de uso del mapudungún inéditos o muy infrecuentes hace sólo un par de décadas.

\subsubsection{Primera lengua declarada}

Se consultó a los participantes por la lengua en que recuerdan haber aprendido a hablar, presentándoles las opciones 'mapudungún', 'castellano' y 'ambas lenguas a la vez'. La opción del mapudungún como L1 recibe el 55\% de las preferencias (22 menciones). El castellano representa el $25 \%$ de las respuestas (10 casos) y finalmente la adquisición simultánea de ambas lenguas reúne el 20\% restante (8 casos).

De las variables descriptivas (sexo, edad y residencia), sólo la edad de los hablantes parece influir en la secuencia de adquisición de lenguas. La indicación de mapudungún como Ll muestra valores decrecientes según los distintos grupos de edad: 71,4\% para los mayores, $57,1 \%$ para los adultos, y 33,3\% para los jóvenes. Esta secuencia se invierte al observar las declaraciones de castellano como primera lengua exclusiva: jóvenes $(41,7 \%)$, adultos $(28,6 \%)$ y mayores $(7,1 \%)$. Las respuestas de adquisición simultánea, en tanto, se distribuyen con relativo equilibrio entre los tres grupos de edad.

\subsubsection{Agentes de transmisión}

En relación con este ítem, se situaba al entrevistado en su infancia y se le pedía que mencionara a las personas de quienes había aprendido directamente el mapudungún. La pregunta no incluía opciones previas; además, el hablante podía indicar hasta tres agentes, especificando el orden jerárquico de sus elecciones.

Las primeras menciones se distribuyen casi exclusivamente entre las generaciones de padres y abuelos, con una leve preferencia para los primeros: $51,2 \%$ versus $41 \%$, que equivalen al subtotal de menciones para cada grupo generacional ( 20 y 16, respectivamente), para un total de 39 respuestas recogidas. Las 3 menciones restantes se distribuyen entre 'hermanos' y 'gente de la comunidad'. Aun cuando algunas respuestas remiten a agentes genéricos ("ambos padres", "gente de la comunidad", etc.), se registró un predominio amplio de las mujeres como agentes de transmisión de la lengua. En total, el 51,2\% de preferencias se dirige a alguna figura femenina individualizada (20 respuestas, distribuidas 
equitativamente entre la madre y alguna abuela) versus un 15,3\% de menciones explícitas para sus pares masculinos ( 6 respuestas, sumando padre y abuelo).

En cuanto a los agentes identificados en segunda preferencia, las respuestas se distribuyen en distintos agentes del núcleo familiar (exceptuando la categoría colectiva 'ambos padres'). Destacan 9 menciones a 'tíos y otros parientes', como también 4 menciones explícitas a 'hermanos' del hablante. En una mirada general a las respuestas, aparecen menciones a otras categorías colectivas con distinto orden jerárquico: 'gente de la comunidad' (2-2-5) y 'compañeros de escuela' (0-2-5). Por último, 11 participantes no otorgaron ninguna mención a sus padres en tanto agentes de transmisión del mapudungún.

Al igual que en la identificación de la primera lengua, sólo la variable 'edad' se relaciona con las respuestas sobre agentes de transmisión. Los datos muestran diferencias claras, sobre todo entre los grupos de edad no adyacentes. Así, mientras los mayores privilegian a la generación de los padres, entre los jóvenes prevalece la generación de los abuelos. Por su parte, el grupo de adultos distribuye sus preferencias con bastante equilibrio entre padres y abuelos. Si se considera el agente que recibe más menciones en cada grupo de edad, se obtiene que para los mayores es la madre, mientras que para adultos y jóvenes es la abuela.

\subsubsection{Agentes de transmisión y primera lengua declarada}

En este caso, se retoman las tres categorías de primera lengua declarada (mapudungún, castellano y ambas lenguas) y se cruzan con el agente principal de transmisión del mapudungún. Como es de esperar, entre quienes declaran el mapudungún como $\mathrm{Ll}$ predominan los agentes paternos: $72,7 \%$ (16 preferencias sobre un total de 22 respuestas). Aquí destaca la figura de la madre con 8 menciones; la opción 'ambos padres' concentra 5 preferencias y, por último, la figura del padre reúne las 3 menciones restantes. Se registraron también 2 casos en que el hablante identifica a alguna figura paterna como agente principal de transmisión del mapudungún, mientras que declara como primera lengua el castellano.

Los resultados, hasta aquí expuestos, permiten proyectar perfiles sociolingüísticos específicos dentro de la muestra de hablantes, sobre todo en función de la variable 'edad'. Así, entre los mayores predomina la adquisición del mapudungún como primera lengua, que se adquiere en la socialización familiar, con los padres del hablante como principales 
agentes de transmisión, con un rol más protagónico para la figura materna. En los jóvenes, en cambio, la tendencia principal es la adquisición del mapudungún como segunda lengua, proceso en el que cabe mayor participación a la generación de abuelos, con un rol más protagónico para las abuelas.

\subsubsection{Uso del mapudungún con los padres}

También en relación con la infancia de los participantes, se consultó por el idioma que sus padres ${ }^{5}$ usaban regularmente para dirigirse a ellos y viceversa. Las respuestas a ambas preguntas se presentan en la siguiente Tabla.

Tabla 1. Uso del mapudungún con los padres

\begin{tabular}{|l|c|c|}
\hline & Idioma usado por padres & Idioma usado por hijos \\
\hline Mapudungún & $20(50 \%)$ & $17(42,5 \%)$ \\
\hline Castellano & $6(15 \%)$ & $9(22,5 \%)$ \\
\hline Ambos idiomas & $14(35 \%)$ & $14(35 \%)$ \\
\hline Totales & $40(100 \%)$ & $40(100 \%)$ \\
\hline
\end{tabular}

El uso exclusivo (o predominante) del mapudungún por parte de los padres se presenta como la opción principal, con un 50\% de las respuestas. Luego, si se suma el uso alternado de ambos idiomas, se obtiene una percepción de uso del mapudungún (exclusivo/predominante o alternado) equivalente a un $85 \%$, en el caso de los padres. Como contraparte, el uso exclusivo del castellano equivale al 15\% de las respuestas. Las respuestas también indican un uso mayoritario del mapudungún en los hablantes encuestados, aunque menor que el de sus padres: $42,5 \%$ para uso exclusivo/predominante, y $35 \%$ para uso alternado, con una percepción de uso del mapudungún en la infancia que abarca al $77,5 \%$ de la muestra. En padres e hijos, el uso exclusivo/ predominante del castellano es la opción minoritaria: 15\% y 22,5\%, respectivamente; pero si se consideran los usos alternados, los indicadores suben a $50 \%$ y $57,5 \%$ en el mismo orden.

Del análisis anterior surgen dos elementos que requieren mayor atención. Por un lado, la categoría de respuesta 'ambos idiomas', que en nuestro análisis hemos conceptualizado como 'usos alternados'. El segun-

5 Se registraron 4 casos de crianza con los abuelos. En los cuatro casos, tanto padres como abuelos eran hablantes de mapudungún. Por esta razón, se incluyeron estos casos en el procesamiento de estos resultados. 
do aspecto dice relación con la diferencia registrada entre declaraciones de mapudungún como primera lengua (55\%) y el uso de esta lengua en la interacción con los padres (42,5\%). La diferencia (12,5\%) equivale a 5 casos. Por las características del método utilizado (auto-declaraciones) se pueden atribuir estas diferencias a factores subjetivos (actitudes o ideologías lingüísticas) en la elección de respuestas, no en el sentido de tergiversar la experiencia referida, sino producto de representaciones que superponen recuerdos y testimonios, o como una actitud del hablante por legitimar esa condición en la situación de entrevista.

\subsubsection{Bilingüismo en la infancia}

En relación con el punto anterior, se intentó precisar el perfil lingüístico de los entrevistados durante su socialización temprana. Para ello se tomaron como punto de partida los datos sobre uso lingüístico de padres e hijos. A cada opción de respuesta se le asignó un código como se indica: mapudungún (0), castellano (1), y ambas lenguas (2). De este procedimiento surgieron nueve combinaciones posibles. En las respuestas registradas (ver Tabla 2), se verifican 6 de estas 9 combinaciones, las que se agruparon en 4 categorías descriptivas. Los resultados de este análisis se presentan en la Tabla 2.

Tabla 2. Bilingüismo en la infancia, categorías descriptivas

\begin{tabular}{|c|c|c|c|c|}
\hline Uso de $\mathrm{M}$ en padres & Uso de M en hijos & Categoría & Casos & Porcentaje \\
\hline 0 & 0 & Monolingüe en mapudungún & 14 & $35 \%$ \\
\hline 0 & 2 & \multirow[t]{2}{*}{ Bilingüe activo } & \multirow{2}{*}{15} & \multirow{2}{*}{$37,5 \%$} \\
\hline 2 & 2 & & & \\
\hline 0 & 1 & \multirow[t]{2}{*}{ Bilingüe pasivo } & \multirow{2}{*}{5} & \multirow{2}{*}{$12,5 \%$} \\
\hline 2 & 1 & & & \\
\hline 1 & 1 & Monolingüe en castellano & 6 & $15 \%$ \\
\hline & & Total & 40 & 100 \\
\hline
\end{tabular}

- 'Monolingües en mapudungún' son aquellos hablantes que en relación con su infancia declaran un uso exclusivo y consistente de la lengua mapuche con sus padres. Se registraron 14 casos (35\%).

- La categoría 'bilingües activos' representa los casos en que el hablante declara un uso alternado de ambas lenguas en la interacción con sus padres, mientras éstos fluctuaban entre un uso exclusivo del mapudungún o un uso alternado de ambas lenguas. Se registraron $15 \operatorname{casos}(37,5 \%)$. 
- La categoría 'bilingües pasivos' responde a los casos en que los padres hablaban mapudungún o ambas lenguas con sus hijos (nuestros entrevistados), mientras éstos lo hacían solo en castellano. Se registraron 5 casos (12,5\%).

- Por último, la categoría 'monolingües en castellano' representa los casos en que el uso exclusivo del castellano por parte de los padres coincidía con un uso exclusivo del castellano por parte de nuestros entrevistados. Se presentaron 6 casos (15\%).

\subsubsection{Transmisión intergeneracional}

Las categorías señaladas en el punto anterior permiten abordar con mayor precisión la transmisión intergeneracional del mapudungún en la muestra estudiada. En términos operacionales, se propone un indicador de transmisión intergeneracional como resultado de la relación entre el perfil lingüístico de los padres y el desarrollo de competencia activa en mapudungún de nuestros entrevistados durante su primera infancia. Esto implica que la competencia pasiva será considerada como manifestación de un quiebre en la transmisión del mapudungún entre una generación y otra, lo cual no excluye la posibilidad de una activación posterior de la lengua a través de medios o agentes compensatorios. Los resultados del análisis se presentan en la Tabla 3.

Tabla 3 Transmisión intergeneracional

\begin{tabular}{|l|c|c|c|c|c|}
\hline \multirow{2}{*}{$\begin{array}{l}\text { Bilingüismo en la infancia, } \\
\text { categorías descriptivas }\end{array}$} & \multicolumn{3}{|c|}{ ¿Los padres hablan mapudungún? } & Total \\
\cline { 2 - 6 } & Ambos & $\begin{array}{c}\text { Sólo el } \\
\text { padre }\end{array}$ & $\begin{array}{c}\text { Sólo la } \\
\text { madre }\end{array}$ & Ninguno & \\
\hline $\begin{array}{l}\text { monolingüe en } \\
\text { mapudungún }\end{array}$ & $\begin{array}{c}12 \\
(35,3 \%)\end{array}$ & 0 & $\begin{array}{c}2 \\
(100 \%)\end{array}$ & 0 & $\begin{array}{c}14 \\
(35 \%)\end{array}$ \\
\hline bilingüe activo & $\begin{array}{c}15 \\
(41,4 \%)\end{array}$ & 0 & 0 & 0 & $\begin{array}{c}15 \\
(37,5 \%)\end{array}$ \\
\hline bilingüe pasivo & $\begin{array}{c}4 \\
(1,8 \%)\end{array}$ & $\begin{array}{c}1 \\
(33,3 \%)\end{array}$ & 0 & 0 & $\begin{array}{c}5 \\
(12,5 \%)\end{array}$ \\
\hline monolingüe en castellano & $\begin{array}{c}3 \\
(8,8 \%)\end{array}$ & $\begin{array}{c}2 \\
(66,7 \%)\end{array}$ & 0 & $\begin{array}{c}1 \\
(100 \%)\end{array}$ & $\begin{array}{c}6 \\
(15 \%)\end{array}$ \\
\hline Total & $\begin{array}{c}34 \\
100 \%\end{array}$ & $\begin{array}{c}3 \\
100 \%\end{array}$ & $\begin{array}{c}2 \\
100 \%\end{array}$ & $\begin{array}{c}1 \\
100 \%\end{array}$ & $\begin{array}{c}40 \\
100 \%\end{array}$ \\
\hline
\end{tabular}

Un rasgo sociolingüístico relevante es la alta proporción de ambos padres hablantes de mapudungún: $85 \%$, que equivalen a 34 casos. De este grupo, 27 hablantes desarrollaron competencia activa en mapudungún durante su infancia. Estos casos se distribuyen entre monolingües en mapudungún (12 casos) y bilingües activos (15 casos). A ellos, se 
deben sumar los dos casos que figuran bajo la columna 'sólo la madre', y que se comenta más abajo. En total, según este procedimiento, la transmisión intergeneracional del mapudungún se verifica en el 72,5\% de la muestra.

Como contraparte, se presenta una interrupción de la transmisión lingüística en el otro $27,5 \%$ de la muestra. Lo interesante de estos casos es que indican también casos de activación tardía del bilingüismo. A partir de estos datos, se puede intentar una primera aproximación a las condiciones en que se da el bilingüismo tardío en los hablantes urbanos. En primer lugar, están los 7 hablantes que no desarrollaron competencia activa en mapudungún durante su infancia, pese a que sus padres (ambos) figuran también como hablantes de mapudungún. Éstos 7 casos se distribuyen entre bilingües pasivos (4) y monolingües en castellano (3). Esta distinción supone diferentes orientaciones hacia la participación de los sujetos en los eventos comunicativos en mapudungún que se desarrollan en el contexto de la socialización familiar. En este punto, conviene entender la competencia pasiva como un estado de latencia, con cierta presencia de input lingüístico que posteriormente el hablante puede desarrollar de manera activa.

Las siguientes columnas presentan los datos de 5 casos en que sólo uno de los padres (en 3 casos es el padre y en 2, la madre) responde a la condición de hablante de mapudungún. Aunque se trata de un rasgo minoritario, las respuestas presentan una regularidad que merece ser destacada: si es sólo el padre quien habla mapudungún, los hijos desarrollan competencia monolingüe en castellano ( 2 casos) o competencia pasiva del mapudungún ( 1 caso). Al contrario, si es la madre la que habla mapudungún, los hijos desarrollan competencia activa como monolingües de mapundungún (en los 2 casos). Por último, en la Tabla 3 se indica el caso de un hablante que comparte con sus padres la condición de monolingüe en castellano. En este caso, la interrupción de la transmisión del mapudungún parece ser asunto consumado en la generación de los padres del hablante. En síntesis, la transmisión intergeneracional del mapudungún se verifica en sus dos modalidades (monolingües y bilingües activos) en 29 casos, que equivalen al $72,5 \%$ de la muestra. En contraste, dicha transmisión aparece interrumpida en un grupo minoritario, pero significativo de casos (11 hablantes, 27,5\%).

Otro dato relevante para comprender esta vinculación con el mapudungún es la edad en que los sujetos sitúan el inicio de la competencia activa en la lengua. El grueso de estos hablantes (8 de 11) indica el período comprendido entre los 15 y los 24 años de edad. Se trata, por 
lo general, de una etapa de definición de la identidad étnico-cultural de los sujetos, por lo que se puede suponer una relación estrecha entre ambos procesos. En otros 3 casos, la competencia activa en la lengua comienza a desarrollarse en torno a los 10 años, etapa en que el hablante tiene menor grado de conciencia respecto de la práctica activa del idioma y su vínculo con la pertenencia o identificación étnica. ${ }^{6}$ Resta un último caso que escapa a las concepciones convencionales que se tienen respecto de la activación tardía en lenguas minorizadas. En este caso, la hablante declara haber desarrollado la habilidad para hablar el mapudungun a los 32 años de edad. Sólo un análisis en profundidad de la experiencia particular de esta hablante autoriza a emitir alguna interpretación respecto de los elementos que definen su vinculación actual con la legua mapuche.

\section{Síntesis y discusión de los resultados}

El objetivo de este artículo ha sido describir algunas características básicas del bilingüismo, en una muestra diversificada de hablantes urbanos de mapudungún. En concreto, el análisis se ha centrado en las características del proceso de adquisición de la lengua mapuche. El primer paso ha sido identificar la posición que ocupa el mapudungún en la secuencia de adquisición de lenguas. Para tal efecto, se consideraron datos de dos tipos: 1) auto-declaraciones de primera lengua, y 2) perfiles de bilingüismo derivados de las pautas de interacción con los padres en la infancia de hablante. De la comparación de respuestas obtenidas con cada procedimiento, se obtuvieron algunos resultados de interés. Por ejemplo, la adquisición del mapudungún como primera lengua exclusiva representa un 55\% de la muestra en las auto-declaraciones, mientras que sólo representa un 35\% si se consideran las pautas de interacción. En parte, esta diferencia se ve compensada por un aumento en los porcentajes de adquisición simultánea (de 20\% a 35\%) y, en menor medida, de la adquisición del mapudungún como L2 (de 25\% a 30\%)

De ambos procedimientos se obtiene una proyección numéricamente favorable para el mapudungún en la socialización temprana. Sin embargo, la reorganización de las auto-declaraciones mediante la elaboración indirecta de pautas de interacción sugiere las siguientes observaciones:

6 También, la referencia a una edad de transición entre la infancia y la adolescencia remite a la eventual superposición de planos temporales que se ha planteado en relación con las diferencias registradas entre adquisición y uso del mapudungún en la infancia. 
El proceso de adquisición de lenguas parece no desarrollarse en términos secuenciales estrictos (es decir, una lengua como Ll y otra como L2). Los antecedentes que se han examinado sugieren la presencia de un input lingüístico permanente aunque en distinto grado para ambas lenguas. Se trataría principalmente de entornos de socialización bilingües. Lo anterior sería válido tanto para hablantes que señalan una socialización primaria como monolingües de mapudungún, como también para quienes señalan una socialización monolingüe en castellano, aunque con matices diferentes.

Un aspecto importante en este punto es la edad de los hablantes, puesto que las experiencias particulares de socialización se insertan en contextos temporales vinculados a distintas disposiciones hacia la transmisión de la lengua y otros valores culturales. ${ }^{7}$ Si se tienen en cuenta las características históricas del proceso migratorio mapuche, ${ }^{8}$ es muy probable que en el caso de los mayores (51 a 78 años), la transmisión de la lengua haya procedido en un contexto ideológico de mayor apego a los valores de la cultura propia, situación que se habría transformado de manera abrupta para los adultos ( 36 a 50 años) y jóvenes ( 20 a 35 años). No obstante, la inserción de la escuela en las propias comunidades constituiría en la experiencia de los mayores el principal punto de quiebre hacia disposiciones colectivas de desarraigo e incluso rechazo y auto-represión hacia la lengua mapuche en beneficio del castellano. Lo anterior se puede proyectar a otros ámbitos como la religión, la organización social, las condiciones de residencia, etc.

Del mismo modo, es probable que las actitudes hacia la lengua de los hablantes jóvenes se vean permeadas por el clima de revalorización de lo étnico que se ha evidenciado en las últimas décadas, en directa relación con los procesos sociopolíticos de reivindicación étnica de los mapuches urbanos (Aravena, 2002). El problema sociolingüístico no se limita a las elecciones funcionales de tal o cual código en la interacción comunicativa, sino que pone de relieve un conflicto sociocultural marcado por disputas no resueltas que emanan de las posiciones hegemónicas o subalternas de los distintos grupos asociados a una u otra lengua, en este caso español y mapudungún (Muñoz, 2006; Giannelli, 2008b).

El segundo aspecto abordado se refiere a los agentes de transmisión de la lengua. Una evaluación preliminar de los resultados sugiere un cuadro amplio de agentes de transmisión y socialización del mapudungún en

7 Véase, entre otros, Fernández y Hernández (1984) y Durán y Ramos (1989).

8 Al respecto, véase Munizaga (1961), Bengoa (1996) y Aravena (2002), entre otros 
el ambiente familiar, con un papel principal a cargo de los padres y en segundo plano los abuelos del hablante, con predominio de los agentes femeninos por sobre los masculinos. Este cuadro se complementa con indicaciones minoritarias a hermanos, tíos y otros parientes. Esta diversidad de agentes en el entorno familiar del hablante sugiere, en principio, la posibilidad de contextos de socialización caracterizados por una práctica constante y consistente del mapudungún entre los miembros del grupo familiar inmediato. ¿En qué medida esa imagen favorable para una socialización temprana en mapudungún concuerda con intentos explícitos, sostenidos y generalizados de transmisión lingüística en el entorno familiar del hablante?

El examen de datos complementarios puede ayudar a despejar esta interrogante. Primero, la mención a agentes que no forman parte del núcleo familiar del hablante ('gente de la comunidad' o 'compañeros de escuela') se presenta como compensación a una baja (e incluso nula) participación de agentes tradicionales en la experiencia de algunos participantes. Segundo, los 11 casos (27,5\% de la muestra) en que el hablante no otorga mención alguna a sus padres en el proceso de transmisiónadquisición del mapudungún. Tercero, la mayor presencia de las figuras femeninas entre los agentes de transmisión. El dato más ilustrativo aquí es el protagonismo de las figuras maternas en los contextos familiares mixtos. Considerados en conjunto, estos datos sugieren que dentro de este panorama amplio de agentes, la transmisión del mapudungún no surge en un contexto de interacciones cotidianas y fluidas entre los mayores y las nuevas generaciones de hablantes, sino que recae selectivamente en algunas figuras específicas del entorno familiar inmediato del hablante, o incluso en algunos agentes externos a la red familiar. Lo anterior puede ser válido no sólo para quienes se ajustan al perfil de hablantes de mapudungún como L2, sino también para quienes proyectan un vínculo propio de la adquisición de lengua materna.

Estos antecedentes refuerzan la imagen de un conflicto sociolingüístico subyacente en el proceso de transmisión-adquisición del mapudungún, no sólo aplicable a la situación de los hablantes urbanos, sino también a los contextos de socialización tradicionales. Debe recordarse en este punto que la muestra estudiada, a pesar de ser caracterizada en términos de 'hablantes urbanos', se constituye casi en su totalidad por hablantes que se criaron y se formaron en el espacio social de las comunidades e, incluso, algunos de ellos mantienen un regimen de doble residencia que les permite interactuar tanto en el espacio urbano como en la comunidad. 


\section{Conclusiones}

Las investigaciones sobre la situación sociolingüística del mapudungún en Chile muestran datos concretos respecto de la posición minorizada de esta lengua, tanto en relación con el contexto nacional, como dentro del mismo contexto social mapuche. Esta relación se acentúa en el medio urbano. En general, las investigaciones han utilizado los métodos convencionales propios de una sociología del lenguaje descriptiva: se dimensiona el problema, se identifican sus causas y se elaboran pronósticos a futuro. Por contrapartida, escasos han sido los esfuerzos por indagar y comprender el dinamismo interno de los fenómenos de pérdida, mantenimiento y recuperación de la lengua, salvo en cuanto al primero de estos procesos.

Los resultados que se han analizado en este trabajo muestran que la vinculación de los hablantes con el mapudungún se caracteriza por una tensión permanente entre orientaciones eventuales hacia la pérdida o la recuperación de la lengua ${ }^{9}$. Estos procesos se relacionan de manera directa con las condiciones de socialización temprana de los hablantes, en especial, la influencia que tienen las disposiciones ideológicas del entorno familiar en el posterior desarrollo del bilingüismo en los sujetos. Resultados significativos que ilustran lo anterior son: 1) las diferencias registradas entre auto-declaraciones de primera lengua y las pautas de interacción con los padres; 2) la tensión implícita en el alto porcentaje de 'ambos padres hablantes' y la menor participación de éstos en relación con los abuelos como agentes de transmisión; 3) la composición variada de agentes de transmisión, que incluía también agentes ajenos al núcleo familiar directo; 4) la activación tardía de un porcentaje significativo de hablantes que componen la muestra. Probablemente sea este último punto el hallazgo más relevante que surge del análisis de resultados, pues los datos que aquí hemos analizado parecen apuntar hacia experiencias de desarrollo del bilingüismo mapuche en contextos de rechazo explícito para tal propósito.

La identificación de factores que tornan complejo y heterogéneo el proceso de adquisición de la lengua es un punto de partida relevante para intentar comprender cómo se configura la relación entre identidad étnica y comportamiento socio-lingüístico en hablantes de lenguas minorizadas. En Wittig (2009), se presenta un análisis parcial sobre la intersección de estas dos dimensiones en las experiencias de adquisición

9 En un sentido similar a lo discutido por Muñoz (2006) y Durán et al. (2007). 
tardía del mapudungún de estos hablantes. Sobre la base de testimonios y discursos reflexivos de los hablantes urbanos se muestra, por un lado, el carácter conflictivo que implica asumir esa condición en la ciudad $y$, por otro, los comportamientos con que éstos intentan mantener una práctica del idioma coherente con los procesos de identificación étnica que tienen lugar en ese medio.

La vinculación del hablante con la lengua se construye en el proceso de socialización familiar y formación de la identidad cultural de la persona. No obstante, la relación entre lengua e identidad se moldea como respuesta a factores heterogéneos en una dialéctica permanente al interior de las distintas redes sociales en las cuales participan los hablantes en sus distintas etapas y esferas de socialización (Sichra, 2004), que incluye -en este caso- la experiencia urbana. Desde esta perspectiva, los datos analizados en este artículo sugieren no sólo procesos individuales de sustitución de la lengua, sino que también se proyectan como puntos de partida para esfuerzos deliberados con que los sujetos intentan situar y validar su condición de hablante en el medio urbano.

\section{Bibliografía}

Albó, X. (1988). "El futuro de los idiomas oprimidos". En Orlandi, Eni P. (edit). Política lingüística na America Latina. Campinas: Pontes; pp. 75-104.

Aravena, A. (2002). "Los Mapuche-Warriache: migración e identidad mapuche urbana en el siglo XX". En Boccara, G. (ed.) Colonización, resistencia y mestizaje en las Américas. Quito: Abya-Yala, pp. 359-385.

Bengoa, J. (1996). "Población, familia y migración mapuche. Los impactos de la modernización en la sociedad mapuche, 19821985". En Pentukun, 6: 9-28.

CONADI-UTEM (2009). Perfil sociolingüístico de las lenguas aymara y mapuche en la Región Metropolitana. Santiago de Chile: CONADI.

Coronado, G. (1996). "El Bilingüismo como alternativa frente a la diversidad". En Muñoz Cruz y Lewin (comp.) El significado de la diversidad lingüistica y cultural. México: UAM (Itzapalapa) -INAH (Oaxaca), pp: 49-66.

Durán, T; Catriquir, D. y Hernández, A. (2007). "Revitalización del mapuzugun. Una visión crítica desde la educación 
intercultural, la sociolingüística y la antropología." En Durán, T.; Catriquir, D. y Hernández, A. (compiladores): Patrimonio cultural mapunche. Volumen 1. Derechos Lingüísticos y Patrimonio Cultural Mapunche. Temuco: Editorial UC Temuco, pp: 107-125.

Durán, T. y Ramos, N. (1989). "Interacción mapudungun-castellano vinculada a contextos educacionales en una población mapuche rural". En Lenguas Modernas, 16, pp: 97114 .

Fasold, R. (1996). La sociolingüistica de la sociedad. Introducción a la sociolingüística. Madrid: Visor.

Fernández, I. y Hernández, A. (1984). "Estudio exploratorio de actitudes lingüísticas en una situación de bilingüismo. El caso mapuche". En RLA 22: 35-51.

Fishman, J. (1982). Sociología del lenguaje. Madrid: Cátedra.

(1991). Reversing language shift. Clevedon: Multilingual matters.

Giannelli, L. (2008a). "Dominios y redes de empleo del mapuzugun en el marco rural mapuche". En Signos Lingüísticos, 10 (5): $99-122$

(2008b). "La lengua nativa entre los mapuches urbanizados de Santiago de Chile. Un ejemplo de análisis en el marco de la hegemonía lingüístico-cultural". En NAE 24: 23-31.

Gundermann, H. (2005). "Estudio del contexto sociolingüístico de comunidades aymaras, atacameñas y mapuche de Chile", en Vergara, J. y Gundermann, H. (editores): Descripción del contexto sociolingüístico en comunidades indígenas de Chile, Santiago: Programa EIB (MINEDUC) y Programa Orígenes, pp.13-97.

; Canihuan, J.; Clavería, A. y Faúndez, C. (2008). Perfil sociolingüístico de comunidades mapuches de la Región del Biobio, Araucanía, los Ríos y los Lago. Informe de Investigación. Santiago: CONADI - UTEM.

; y_ (2009). "Permanencia y desplazamiento, hipótesis acerca de la vitalidad del mapuzugun". En RLA vol. 47(1): 37-60.

Hamel, Rainer E. (1988). "La política del lenguaje y el conflicto interétnico. Problemas de investigación sociolingüística". En 
Orlandi, Eni P. (edit). Política lingüística na America Latina. Campinas: Pontes; pp. 41-75.

Hornberger, N. y Coronel-Molina, S. (2004). "Quechua language shift, maintenance and revitalization in the Andes: the case for language planning". En International Journal of the Sociology of Language, 167: 9-67.

Johnstone, B. (2000). Qualitative methods in sociolinguistics. New York: Oxford University Press.

Lagos, C. (2004). La vitalidad lingüística del mapudungún en Santiago de Chile, sus factores determinantes y consecuencias socioculturales. Estudio exploratorio desde una perspectiva socio y etnolingüística. Tesis para optar al grado de Magíster en Lingüística, Universidad de Chile.

Moreno Fernández, F. (2005). Principios de sociolingüística y sociología del lenguaje. Barcelona: Ariel.

Munizaga, C. (1961). Estructuras transicionales en la migración de los araucanos de hoy a la ciudad de Santiago de Chile. Notas del Centro de Estudios Antropológicos, No. 6. Santiago: Universidad de Chile.

Muñoz Cruz, H. (2006). "Cambio sociolingüístico y experiencias interculturales desde discursos autobiográficos de hablantes de lenguas indígenas". En Cuadernos Interculturales, 7 , pp. 23-48.

Patton, M. Q. (1990). Qualitative evaluation and research methods. Second edition. New York: Sage.

Salas, A. (1987). "Hablar en mapuche es vivir en mapuche. Especificidad de la relación lengua/cultura". En RLA vol. 25, 27-35, Universidad de Concepción.

Sichra, I. (2004). "Identidad y lengua”, en Samaniego, M. y Gabarini, C. G. (comps) Rostros y fronteras de la identidad. Santiago: Pehuén, pp: 209-234.

Wittig, F. (2009). "Desplazamiento y vigencia del mapudungún en Chile: un análisis desde el discurso reflexivo de los hablantes urbanos", en RLA, vol. 47(2): 135-155.

Zúñiga, F. (2007). "Mapudunguwelaymi am? 'iAcaso ya no hablas mapudungun?' Acerca del estado actual de la lengua mapuche". En Estudios Públicos, 105: 9-24. 